\title{
ANALISIS JENIS DAN KADAR SAPONIN EKSTRAK METANOL DAUN KEMANGI (Ocimum basilicum L.) DENGAN MENGGUNAKAN METODE GRAVIMETRI
}

\author{
Saponin Analysis of Kemangi Leaf Methanol Extract (Ocimum basilicum L.) \\ by Gravimetry Method \\ Mauritz Pandapotan Marpaung dan Romelan \\ 1,2Fakultas Farmasi, Universitas Kader Bangsa (UKB) Palembang \\ Email: mauritzchem@gmail.com
}

\begin{abstract}
Kemangi plant (Ocimum basilicum L.) is a plant that has benefits such as overcoming nausea, abdominal bloating, fever, essential oils, vegetable pesticides, fresheners and as a medicine. Kemangi leaves contain phytochemical compounds such as tannins and saponins. The purpose of this research is to analyze the type and content of saponin on kemangi leaf extract by color test and gravimetric method. Samples of kemangi leaves were obtained from Betung area, Banyuasin regency, South Sumatera. Analysis of saponin content, kemangi leaf extract was done by using reflux extraction with methanol solvent. The results showed that the results of the color test, the type of saponin contained from kemangi leaf extract is saponin steroid and the saponin content produced from kemangi leaf extract was $3.11 \pm$ $0.0795 \%$.
\end{abstract}

Keywords: Kemangi leaf, saponin, gravimetry

\begin{abstract}
Abstrak
Tanaman kemangi (Ocimum basilicum L.) merupakan tanaman yang mempunyai manfaat seperti mengatasi mual, perut kembung, demam, penghasil minyak atsiri, pestisida nabati, penyegar dan sebagai obat. Daun kemangi mengandung senyawa fitokimia berupa tanin dan saponin. Tujuan dari penelitian ini adalah untuk menganalisis jenis dan kadar saponin pada ekstrak daun kemangi dengan uji warna dan metode gravimetri. Sampel daun kemangi diperoleh dari daerah Betung, Kabupaten Banyuasin, Sumatera Selatan. Analisis kadar saponin, ekstrak daun kemangi dilakukan dengan menggunakan ekstraksi refluks dengan pelarut metanol. Hasil penelitian menunjukkan bahwa dari hasil uji warna, jenis saponin yang terkandung dari ekstrak daun kemangi adalah saponin steroid dan kadar saponin yang dihasilkan dari ekstrak daun kemangi adalah 3,11 \pm 0,0795\%.
\end{abstract}

Kata Kunci: Daun kemangi, saponin, gravimetri i

\section{PENDAHULUAN}

Pemanfaatan tanaman berkhasiat obat oleh masyarakat merupakan salah satu upaya dalam menanggulangi masalah kesehatan khususnya untuk mengobati penyakit. Obat tradisional menjadi pilihan karena mudah dijangkau masyarakat, baik harga maupun ketersediaan bahannya [1]. Tanaman kemangi (Ocimum basilicum L.) merupakan salah satu tanaman berkhasiat obat yang ada di Indonesia. Tanaman kemangi secara empiris telah digunakan sebagai obat tradisional masyarakat yang diolah secara sederhana untuk mengobati berbagai 
gangguan kesehatan pada manusia, diantaranya yaitu untuk mengatasi mual, perut kembung dan demam [2,3]. Selain itu, tanaman ini juga mempunyai banyak manfaat sebagai obat, pestisida nabati, penghasil minyak atsiri, sayuran dan penyegar [4]. Daun kemangi juga memiliki kandungan senyawa fitokimia berupa tanin dan saponin [5].

Saponin adalah detergen atau glikosida alami yang mempunyai sifat aktif permukaan yang bersifat amfifilik, mempunyai berat molekul besar dan struktur molekulnya terdiri dari aglikon steroid atau triterpen yang disebut dengan sapogenin dan glikon yang mengandung satu atau lebih rantai gula [6]. Kadar saponin dapat dianalisis secara kuantitatif dengan menggunakan metode gravimetri [7]. Selain menggunakan metode gravimetri, metode TLC Scanner dan spektrofotometri Uv-Vis juga dapat digunakan dalam menganalisis kandungan saponin [8,9].

Dalam penelitian ini, metode yang digunakan dalam analisis kadar saponin adalah metode gravimetri. Gravimetri merupakan merupakan cara pemeriksaan jumlah zat yang paling sederhana dibandingkan dengan cara pemeriksaan lainnya karena jumlah zat ditentukan dengan menimbang langsung massa zat yang dipisahkan dari zat-zat lain [10]. Penelitian ini bertujuan untuk menentukan kadar saponin dengan menggunakan metode gravimetri dan jenis saponin yang terkandung dalam ekstrak daun kemangi.

\section{METODE PENELITIAN}

\section{Alat dan Bahan}

Alat alat yang digunakan antara lain batang pengaduk, blender, corong, corong pisah, desikator, erlenmeyer, gelas ukur, gelas kimia, kain kasa, kertas saring (Whatman), labu alas bulat, neraca analitik, oven, pipet tetes, rotary evaporator, tabung reaksi, waterbath, plat tetes.

Bahan-bahan yang digunakan antara lain daun kemangi, akuades, dietil eter, amonia
$0,05 \mathrm{~N}$, asam asetat anhidrat, $\mathrm{H}_{2} \mathrm{SO}_{4} 2 \mathrm{~N}$, etil asetat, $\mathrm{HCl} 2 \mathrm{~N}$, kloroform, metanol, $\mathrm{n}$ butanol dan petroleum eter.

\section{Prosedur Penelitian}

\section{Pengambilan Bahan Uji}

Daun kemangi (Ocimum basilicum L.) yang segar diambil dari tanaman kemangi yang tumbuh di daerah Betung, Kecamatan Banyuasin III, Kabupaten Banyuasin, Sumatera Selatan.

\section{Determinasi Bahan Uji}

Determinasi tanaman kemangi dilakukan di Laboratorium Herbarium Biologi, Fakultas MIPA, Universitas Andalas, Padang.

\section{Pembuatan Ekstrak Daun Kemangi}

Daun kemangi yang segar dibuat simplisia dengan mencuci bersih, lalu dikeringkan di bawah sinar matahari secara tidak langsung dan ditutup dengan kain hitam. Kemudian dihaluskan dan diayak untuk memperoleh serbuk halus. Lalu sebanyak 50 gram serbuk simplisia daun kemangi direfluks dengan metanol $(1: 10)$ selama 30 menit pada suhu $50-60^{\circ} \mathrm{C}$. Sari metanolik dipisahkan dari ampas dan diuapkan dengan rotary evaporator pada suhu $50^{\circ} \mathrm{C}$ sampai diperoleh ekstrak kental daun kemangi. Lalu dihitung ditimbang dan dihitung rendemennya.

\section{Identifikasi Saponin}

Dimasukkan 0,5 g serbuk simplisia daun kemangi ke dalam tabung reaksi. Lalu ditambahkan $10 \mathrm{~mL}$ air panas, didinginkan dan dkikocok kuat selama 10 detik hingga terbentuk busa dengan tinggi $1-2 \mathrm{~cm}$. Kemudian ditambahkan 1 tetes $\mathrm{HCl} 2 \mathrm{~N}$ melalui dinding tabung reaksi. Pada penambahan 1 tetes $\mathrm{HCl} 2 \mathrm{~N}$, busa tidak hilang berarti sampel mengandung saponin [11]. 


\section{Penentuan Jenis Saponin}

Dalam tabung reaksi, sebanyak 0,5 g simplisia daun kemangi dimasukkan ke dalam $5 \quad \mathrm{~mL}_{2} \mathrm{H}_{2} \mathrm{SO}_{4} 2 \mathrm{~N}$ lalu dikocok sehingga terbentuk dua lapisan dan dipisahkan. Lapisan bagian bawah (fase minyak) diteteskan pada plat tetes dan dibiarkan mengering. Lalu tambahkan 1-2 tetes asam asetat anhidrat, lalu diaduk. Kemudian ditambahkan 3 tetes $\mathrm{H}_{2} \mathrm{SO}_{4}$ pekat, lalu diaduk. Apabila terbentuk warna biru atau hijau menandakan adanya saponin steroid.

Untuk uji saponin triterpenoid, ditambahkan $5 \mathrm{~mL}$ amonia 0,05 $\mathrm{N}$ dalam kloroform 1-2 tetes, lalu disaring. Filtrat dimasukkan ke dalam tabung reaksi dengan menambahkan $5 \mathrm{~mL} \mathrm{H}_{2} \mathrm{SO}_{4} 2 \mathrm{~N}$. Lalu digojok terbentuk dua lapisan dan dipisahkan.. Lapisan bawah (fase minyak) diteteskan pada plat tetes dan dibiarkan mengering. Kemudian ditambahkan asam asetat anhidrat. Setelah diaduk, kemudian ditambahkan 3 tetes $\mathrm{H}_{2} \mathrm{SO}_{4}$ pekat dan diaduk. Apabila terbentuk warna merah atau ungu menandakan adanya saponin triterpenoid [12].

\section{Penetapan Kadar Saponin secara Gravimetri}

Sebanyak 1,25 g ekstrak kental direfluks dengan $50 \mathrm{~mL}$ petroleum eter pada suhu $60-80^{\circ} \mathrm{C}$ selama 30 menit. Setelah dingin, larutan petroleum eter dibuang dan residu yang tertinggal dilarutkan dalam $50 \mathrm{~mL}$ etil asetat. Larutan dipindahkan ke corong pisah, kemudian dipisahkan larutan etil asetat. Residu yang tertinggal dilarutkan dengan n-butanol sebanyak 3 kali masingmasing dengan $50 \mathrm{~mL}$. Lalu diuapkan dengan rotary evaporator. Sisa penguapan dilarutkan dengan metanol $10 \mathrm{~mL}$, lalu diteteskan ke dalam $50 \mathrm{~mL}$ dietil eter sambil diaduk. Endapan yang terbentuk dalam campuran dituangkan pada kertas saring yang telah diketahui bobotnya, lalu dibilas dengan $10 \mathrm{~mL}$ dietil eter. Kemudian kertas saring dikeringkan dan ditimbang sampai bobot tetap. Selisih bobot kertas saring sebelum dan sesudah penyaringan ditetapkan sebagai bobot saponin. Hal ini dilakukan sebanyak 3 kali dengan hasil perhitungan kadar rata-rata saponin.

\section{Analisa data}

Analisis data kadar saponin dilakukan dengan menggunakan rumus:

$$
\frac{X 2-X 1}{A} \times 100 \%=\cdots \%
$$

Keterangan:

$\mathrm{X} 1$ = bobot kertas saring $(\mathrm{g})$

$\mathrm{X} 2$ = bobot kertas saring + endapan $(\mathrm{g})$

$\mathrm{A}=$ bobot ekstrak daun kemangi $(\mathrm{g})$

\section{HASIL DAN PEMBAHASAN}

Daun kemangi yang diperoleh dari daerah Betung, Kecamatan Banyuasin III, Kabupaten Banyuasin, Sumatera Selatan dilakukan determinasi di laboratorium Herbarium Biologi, FMIPA, Universitas Andalas, Padang menyatakan bahwa daun kemangi yang menjadi sampel penelitian mempunyai spesies Ocimum basilicum L. dengan keluarga Lamiaceae. Setelah melakukan determinasi, kemudian membuat ekstrak daun kemangi yang dimulai dengan sortasi basah dan sortasi kering dan dihaluskan untuk menghasilkan simplisia. Dari $50 \mathrm{~g}$ simplisia yang digunakan dalam ekstraksi melalui refluks dengan menggunakan pelarut metanol dan diuapkan dengan rotary evaporator diperoleh ekstrak kental sebanyak 9,4 gram. Dari ekstrak kental yang diperoleh, didapatkan rendemen sebesar 18,8\%. Ekstraksi dilakukan dengan pelarut metanol karena metanol merupakan pelarut yang paling baik digunakan untuk menarik senyawa saponin. Karena saponin bersifat polar sehingga akan lebih mudah larut daripada pelarut lain [13]

Setelah melakukan ekstraksi, kemudian dilakukan uji kualitatif untuk mengetahui adanya kandungan saponin dalam daun kemangi melalui uji busa. Berdasarkan uji kualitatif, terlihat bahwa sampel membentuk busa stabil dengan ketinggian 1-3 cm yang 
berarti sampel mengandung saponin (Gambar 1).

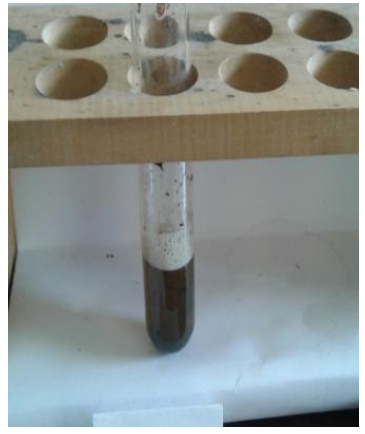

Gambar 1. Hasil uji busa pada sampel ekstrak daun kemangi

Dasar hasil uji busa adalah sifat senyawa saponin yang mudah larut dalam air dan menimbulkan busa ketika dikocok. Busa terbentuk karena saponin merupakan senyawa yang mempunyai gugus hidrofil dan hidrofob. Pada saat digojok, gugus hidrofil akan berikatan dengan air sedangkan gugus hidrofob berikatan dengan udara sehingga membentuk buih. Ditambahkan $\mathrm{HCl} 2 \mathrm{~N}$ untuk menambah kepolaran sehingga gugus hidrofil akan berikatan lebih stabil dan buih yang terbentuk menjadi stabil [14]. Setelah mengetahui adanya kandungan saponin dalam sampel, maka dilakukan uji kualitatif untuk menentukan jenis saponin steroid atau triterpenoid. Berdasarkan hasil uji warna, untuk uji saponin steroid positif menghasikan warna hijau dimana kriteria kandungan saponin steroid apabila menghasilkan warna hijau atau biru (Gambar 2). Sedangkan jenis saponin triterpenoid dinyatakan tidak terkandung dalam sampel karena menghasilkan warna kuning, dimana warna merah atau ungu dinyatakan positif mengandung saponin triterpenoid (Tabel 1).

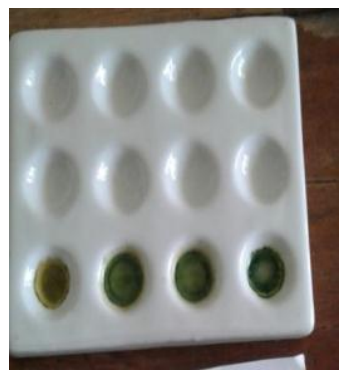

Gambar 2. Hasil Uji warna jenis saponin steroid sampel ekstrak daun kemangi

Tabel 1. Uji warna jenis saponin sampel ekstrak daun kemangi

\begin{tabular}{|l|l|l|l|}
\hline \multicolumn{1}{|c|}{ Pereaksi } & $\begin{array}{l}\text { Hasil } \\
\text { Pengamatan }\end{array}$ & Kriteria & Kesimpulan \\
\hline $\begin{array}{l}\text { Serbuk simplisia }+\mathrm{H}_{2} \mathrm{SO}_{4} 2 \mathrm{~N} \\
\text { dipisahkan }+ \text { asam asetat } \\
\text { anhidrat }+\mathrm{H}_{2} \mathrm{SO}_{4} \text { pekat }\end{array}$ & Warna hijau & $\begin{array}{l}\text { Warna hijau } \\
\text { atau biru }\end{array}$ & $\begin{array}{l}\text { Positif saponin } \\
\text { steroid }\end{array}$ \\
\hline $\begin{array}{l}\mathrm{Serbuk} \text { simplisia }+ \text { amonia 0,05 } \\
\mathrm{N}+\mathrm{H}_{2} \mathrm{SO}_{4} 2 \mathrm{~N}+\text { asam asetat } \\
\text { anhidrat }+\mathrm{H}_{2} \mathrm{SO}_{4} \text { pekat }\end{array}$ & Warna kuning & $\begin{array}{l}\text { Warna } \\
\text { merah atau } \\
\text { ungu }\end{array}$ & $\begin{array}{l}\text { Negatif saponin } \\
\text { triterpenoid }\end{array}$ \\
\hline
\end{tabular}

Saponin adalah suatu senyawa yang memiliki bobot molekul tinggi atau besar, tersebar dalam beberapa tumbuhan, merupakan bentuk glikosida dengan molekul gula yang terikat dengan aglikon triterpen atau steroid. Saponin dikelompokkan menjadi saponin steroid dan saponin triterpen. Saponin steroid memilki komponen dengan inti steroid (C-27) dan terikat dengan molekul karbohidrat. Saponin steroid apabila dihidrolisis menghasilkan aglikon yang disebut sarsaponin. Umumnya saponin steroid memiliki efek sebagai antifungi, dan pada hewan percobaan menghambat aktivitas otot polos. Sedangkan saponin triterpen merupakan senyawa yang berasal dari enam (6) satuan isopren, memiliki struktur inti dengan C-30 yang terikat pada molekul karbohidrat, pada awalnya merupakan rantai asiklik. Triterpen umumnya memiliki gugus alkohol, aldehida dan asam karboksilat, serta berbentuk kristal, tidak berwarna, dan titik lebur tinggi. Saponin triterpen biasanya bersifat asam karena adanya satu atau dua gugus karbonil dalam aglikon dan/atau bagian molekul gula. 
Pada hidrolisis saponin triterpen terbentuk aglikon yang disebut sapogenin [15].

Dengan adanya kandungan saponin dalam ekstrak daun kemangi, maka daun kemangi dapat dijadikan potensi sebagai tanaman obat yang dapat menyembuhkan berbagai penyakit. Hal ini didasarkan bahwa saponin mempunyai efek sebagai antimikroba, menghambat jamur, menurunkan kolesterol, mempunyai sifat sebagai antioksidan, antivirus, antikarsinogenik dan manipulator fermentasi rumen [16]

Setelah menentukan jenis saponin, kemudian dilakukan analisis kadar saponin pada sampel dengan menggunakan gravimetri. Kadar saponin yang dihasilkan dari sampel ekstrak daun kemangi sebesar $3,11 \pm 0,0795 \%$ (Tabel 2).

Tabel 2. Kadar saponin dalam ekstrak daun kemangi

\begin{tabular}{|c|c|c|c|c|}
\hline No & Perlakuan & Bobot ekstrak (g) & $\begin{array}{c}\text { Bobot saponin } \\
(\mathbf{g})\end{array}$ & Kadar saponin (\%) \\
\hline 1. & I & 1,3304 & 0,0427 & $3,20 \%$ \\
\hline 2. & II & 1,2507 & 0,0382 & $3,05 \%$ \\
\hline 3. & III & 1,2508 & 0,0388 & $3,10 \%$ \\
\hline \multicolumn{3}{|c|}{ Rata - rata } & $3,11 \%$ \\
\hline \multicolumn{3}{|c|}{ SD } & 2,0795 \\
\hline
\end{tabular}

Analisis gravimetri merupakan bagian analisis kuantitatif untuk menentukan jumlah zat berdasarkan penimbangan dari hasil reaksi setelah bahan/analit dianalisis diperlakukan terhadap pereaksi tertentu. Hasil reaksi dapat berupa gas atau endapan yang dibentuk dari bahan yang dianalisis [17]. Dalam analisis ini, unsur atau senyawa yang dianalisis dipisahkan dari sejumlah bahan yang dianalisis. Bagian terbesar analisis gravimetri menyangkut perubahan unsur atau gugus dari senyawa yang dianalisis menjadi senyawa lain yang murni dan mantap (stabil), sehingga dapat diketahui berat tetapnya [18].

\section{KESIMPULAN}

Berdasarkan hasil penelitinian ini disimpulkan bahwa jenis saponin yang terkandung dalam ekstrak daun kemangi adalah saponin steroid. Kadar saponin yang terkandung dalam ekstrak daun kemangi adalah $3,11 \pm 0,0795 \%$.

\section{DAFTAR PUSTAKA}

[1] Septiatin, A. 2009. Apotek Hidup dari Tanaman Buah. Bandung: Yrama Widya.

[2] Ismail, M. 2006. Central Properties and Chemical Oil. Pharmaceutical Biology. 44(8):619-626.

[3] Bilal, A., Nasreen, J., Ajij, A., Saima, N. B., Shahida, H., Syeda, H. 2012. Phytochemical and Pharmacological Studies on Ocimum basilicum Linn. International Journal of Current Research and Review (IJCRR). 4(23): 73-83. 
[4] Kardinan, A. 2003. Selasih: Tanaman Keramat Multi Manfaat. Jakarta: Agromedia, 42.

[5] Hamad, A., Jumitera, S., Puspawiningtyas, E., Hartanti, D. 2017. Aktivitas Antibakteri Infusa Kemangi (Ocimum basilicum L.) pada Tahu dan Daging Ayam Segar. Inovasi Teknik Kimia. 2 (1): 1-8.

[6] Sirohi, S.K., Goel, N., Singh, N. 2014. Utilization of Saponins, a Plant Secondary Metabolite in Enteric Methane Mitigation and Rumen Modulation. Annual Research \& Review in Biology.

[7] Mien, J. D., Carolin, A. W., Firhani, A. P. 2015. Penetapan Kadar Saponin pada Ekstrak Daun Lidah Mertua (Sansevieria trifasciata Prain varietas S. Laurentii) secara Gravimetri. Jurnal IImu dan Teknologi Kesehatan. 2(2) : 65-69.

[8] Noer, S., Pratiwi, D. R., Gresinta, E. 2018. Penetapan Kadar Senyawa Fitokimia (Tanin, Saponin, dan Flavonoid sebagai Kuersetin) pada Ekstrak Daun Inggu (Ruta angustifolia L.) Eksakta: Jurnal IImu-Imu MIPA. 19-29.

[9] Minarno, B. E. 2016. Analisis Kandungan Saponin Pada Daun dan Tangkai Daun Carica pubescens Leune \& K. Koch. El-Hayati. 5 (4) : 143-152.

[10] Chadijah, Sitti. 2012. Dasar-Dasar Kimia Analitik. Makassar: Alauddin University Press.

[11] Departemen Kesehatan RI. 1989. Materia Medika Indonesia. Jilid V. Departemen Kesehatan Republik Indonesia.

[12] Kumoro, A. C. 2015. Teknologi Ekstraksi Senyawa Bahan Aktif dari Tanaman Obat. Yogyakarta: Plantaxia.
[13] Harbone, B. J. 1987. Metode Fitokimia: Penuntun Cara Modern Menganalisis Tumbuhan. Bandung: ITB Bandung.

[14] Kumalasari, E, dan Sulistyani, N. 2011. Aktivitas Antifungi Ekstrak Etanol Batang Binahong (Anredera cordifolia (Tenore) Steen.) terhadap Candida albicans serta Skrining Fitokimia. Jurnal IImiah Kefarmasian. 1 (2) : 51-62.

[15] Hanani, Endang. 2015. Analisis Fitokimia. Jakarta: EGC. 227-229.

[16] Suparjo. 2008. Saponin: Peran dan Pengaruhnya bagi Ternak dan Manusia. Fakultas Peternakan. Jambi.

[17] Widodo, D. S dan Lusiana, R. A. 2010. Kimia Analisis Kuantitatif. Yogyakarta: Graha Ilmu.

[18] Gandjar, G. I dan Rohman, A. 2007. Kimia Farmasi Analisis. Yogyakarta: Pustaka Pelajar. 